\title{
Medical Ethics and Human Rights in Reproductive Health
}

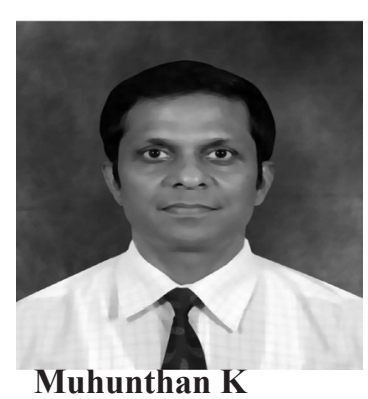

\author{
Muhunthan $\mathrm{K}^{1}$, Arulkumaran $\mathrm{S}^{2}$ \\ ${ }^{1}$ Department of Obstetrics and Gynaecology, University \\ of Jaffna, Sri Lanka, ${ }^{2}$ St George's University of London, \\ President of FIGO, UK.
}

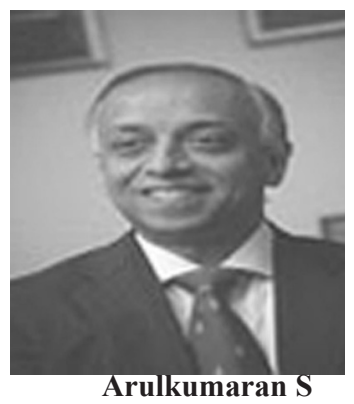

Ethical sensitivity in reproductive health is based on awareness that, in many social and family settings, women have a different, offtern subordinate or disadvantaged, status from that held by men. This is associated with the different social and economic functions that women tend to perform, such as caring for newborn and young children, and disabled and elderly members of their families, rather than being engaged at the forefront of social, economic, and political life. Training in bioethics is required to bring out the best qualities of understanding of and compassion for, their patients in gynecoogy and obstetrics. Training is also required because ethical values increasingly underpin women's human rights entitlements that are expressed in laws. Access to appropriate health care is increasingly recognized to be a human right and legal right, of which medical professionals should be aware. Respect for these rights should be incorporated into clinical practice as an aspect of medical professional ethics and skill.

A challenge for health care providers in bioethical analysis that should precede decision-making is to understand the biases and stereotypes that they bring to the task of decision-making due to their own characteristics and cultural conditioning. Care and training are required to ensure that women patients are not viewed through assumptions and stereotypes that deny or compromise the human rights to which

\section{CORRESPONDENCE}

Dr Kopalasuntharam Muhunthan

Head of the Department, Obstetrics and Gynaecology

University of Jaffna, Sri Lanka.

Email: muhunthk@yahoo.com

Phone: 00940212222545 they are ethically entitled. Human rights are detailed in legally binding or influential international treaties, national constitutions and/or national laws and codes, all reflecting contents of the Universal Declaration of Human Rights. This was proclaimed by the General Assembly of the United Nations in 1948. Rights include, for instance, rights to security of the person, to protection against suffering, cruel, inhuman or degrading treatment and to non-discrimination on grounds such as sex, race colour, religion, national or social origin, and birth or other status. Such individual rights are expressions of the first sentence of the Universal Declaration, "All human beings are born free and equal in dignity and rights." Respecting patients' dignity, whatever their circumstances such as income, age, or origins, goes a long way towards satisfying ethical requirements.

FIGO's sexual and reproductive rights committee has proposed that physicians develop the competencies in the following ten human right principles. These are obtained from FIGO's educational web site - 'Global Library of Women's Medicine' (www.glowm.com) and are provided below:

Right to life: Every one has the right to life $^{1}-$ The physician should be able to discuss and decide the provision and denial of emergency health services. They should provide emergency life saving treatment independent of their personal beliefs. They should have the knowledge how the health care systems can ensure or compromise the right to life.

Health: Every one has the right to the highest attainable standard of physical and mental health. ${ }^{2}$ They should have the knowledge of the impact of availability, acceptability, accessibility and quality 
of care on health outcomes. One should be able to assess the quality of health care services for diverse populations in the community. They should be able to discuss how public health measures for screening of disease and injury prolong life expectancy. Should have the knowledge of how biologic and sociologic diversity influences health care outcomes.

Privacy: Every one has the right to respect for privacy in the field of health care. ${ }^{1}$ One should conduct the consultation, examination and treatment of the patient in a private space and in a manner that ensures privacy and respect. Physicians should recognize when there is a need for the presence of third party or a chaperone to be present. They should maintain the patient's privacy in the presence of a chaperone or other individuals invited by the patient. One should acknowledge and accommodate various cultural attitudes towards modesty.

Confidentiality: Every one has the right to confidentiality in relation to information on health care and health status. ${ }^{1}$ We should maintain patient confidentiality and avoid unnecessary disclosure of information. How confidentiality of all written and digital personal information is maintained should be communicated to the patient. Discuss the potential harm and benefit of release of confidential information to third parties. Discuss how the interpretation of the laws on confidentiality affects the provision of health care for women. Discuss how decision to protect or disclose confidential information are made.

Autonomy and decision-making: Every one has the right to autonomous decision making in matters concerning their health. ${ }^{1}$ We should acknowledge and respect decisions that patient's make about their own health care. One should be cogniscent of the medical, social and cultural considerations that affect patient's decision making. Evaluate the capacity of the individual at any age to give consent. Ensure the 'best interests' and evolving capacity of the child are considered in obtaining consent from children and their legal guardians.

Information: Everyone has the right to receive and impart information related to their health. ${ }^{1}$ Communicate risks, benefits and alternatives of accepting and declining therapies. Offer full disclosure of test results and provide full information unless specifically requested otherwise by the patient. Use language in a manner that is culturally sensitive and understandable to the patient. Provide upto date information in understandable language to assist patients with informed decision-making.

Non-discrimination: No one shall be subject to discrimination of any description in the course of receiving health care. ${ }^{1}$ Discuss how consideration of differences of biology, psychology, pathophysiology, etiology and treatment results in improved health for every one. Discuss the impact of societal and cultural roles and religious practices on health care. Discuss the extent to which women are provided appropriate care in maternity services. Provide optimal health services and establish mutually respectful relationships with men and women of all backgrounds and abilities.

Right to decide number and spacing of children: Every one has the right to decide freely and responsibly on the number and spacing of children and to have access to the information, education and means to enable them to exercise these rights. ${ }^{1}$ Counsel the patients about the risks, benefits and mechanisms of action and how to access services for all methods of contraception and abortion. Discuss the effects of coercion or denial of contraceptive and abortion services upon the short and long term health of a woman and her family. Provide comprehensive preconception counseling. Discuss indications for referral for fertility problems.

Freedom from inhumane and degrading treatment: Every one has the right to be free from torture or cruel, inhuman or degrading treatment or punishment in the field of health care. ${ }^{1}$ Identify and assist victims of physical, psychological and sexual violence and abuse, including domestic violence, trafficking and political rape.

Benefit from scientific progress: Though one of the least known human rights every one has the right to enjoy the benefits of scientific progress and its applications. ${ }^{1}$ Offer up to date relevant information with regards to recent scientific progress. ${ }^{2}$ Use simple and understandable language when explaining the recent scientific progress with regards to her health concern. Explain the limitations if present in implementing new development and acknowledge her right to know the facilities that will offer her the benefits of recent scientific progress.

FIGO urges the national societies to take a lead in teaching medical students and trainees in the above ten 
aspects of human rights based approach to women's health care. The www.glowm.com ${ }^{3}$ web site provides with case examples and more information that would help in learning. Subsequent to such learning individual physicians should consider whether they give care based on these principles and reflect on the care given in difficult circumstances.

\section{ACKNOWLEDGEMENTS}

The authors thank Professors Lesley Regan and Diana Magraine - co-chairs of the sexual and reproductive rights committee of FIGO and their team for producing the ten rights based approach to women's health.

\section{REFERENCES}

1. Sabaratnam A. Integrating Human Rights and Women's Health: An overview. The Global Library of Women's Medicine. [Cited 27th March 2014]. Available from http:// www.glowm.com

2. Donders Y. The right to enjoy the benefits of scientific progress: in search of state obligations in relation to health. Med Health Care and Philos. 2011;14:371-81.

3. The Foundation for The Global Library of Women's Medicine.The Global Library of Women's Medicine: The educational platform for The International Federation of Gynecology and Obstetrics (FIGO). [cited 27th March 2014]. Available from http://www.glowm.com 